\title{
Childhood Lead Poisoning and Associated Health Impacts- A Brief Review
}

\author{
Rida Fatima*, Uniba Tariq, Masooma Mehmood, Ghazala Yaqub*
}

\author{
Department of Environmental Sciences, Kinnaird College for Women, 93-Jail Road, Lahore, Pakistan
}

\begin{abstract}
This brief review article is about childhood lead poisoning and associated health impacts. Lead poisoning is regarded as an important pediatric environmental health issue within the world. Children are considered to be at greater risk of lead poisoning than adults. Various sources of lead incudes soil, air, water, food and lead based paints etc. Exposure to lead particles during the processes of inhalation and ingestion is common in young children. Breastfeeding women with $r$ lead levels may cause lead exposure to the infants. Lead exposure leads to various kinds of diseases even at a very young age like Acute Clinical toxicity, Subclinical toxicity, Haematological toxicity, Neurological toxicity, Brain dysfunctionings, Poor Academic performance, Memory retention problems, Poor problem solving skills. Additionally, the likelihood of ADHD, Hearing loss, Malfunctioning in vitamin D metabolism, Stunted growth, adverse effects in Kidneys, Encephalopathy, Stomach cramps and irritation. Lead concentration in blood can be diagnosed through blood tests.For children, the level greater than $45 \mathrm{mcg} / \mathrm{dL}$ should always be treated. The treatment method used depends upon the concentration level of lead in blood. This elimination of lead from blood will require collaboration and participation of governments at all levels.
\end{abstract}

Keywords- Acute Clinical toxicity, Elimination Encephalopathy, Haematological toxicity, Subclinical toxicity.

\section{INTRODUCTION}

Lead is a naturally occurring compound that is found within the Earth's Crust. Increase in population and economic growth has elevated its concentration within the atmosphere for more than six orders of magnitude over the past six millennia, its extensive exposure to human beings results in lead poisoning [1].Lead poisoning is regarded as a most vital pediatric environmental health issue within the world. Childhood is regarded as the most crucial phase of the individual's development but if a child's cognition gets harmed by the exposure of lead, the effects would remain permanent and even continue later, in his adulthood. Each year about 4 Million children in the world gets affected by lead poisoning .Exposure to lead (even at low concentrations)can have fatal health impacts. If the levels of lead in blood lies in the range between 0.48 to $0.97 \mathrm{zmol} / \mathrm{L}$ it is not considered to be safe and results in the variety of health related issues. Lead poisoning occurs when too much lead is absorbed in the body of a child through swallowing or breathing of a substance which consists of lead in it (that can be dust, paint water or food etc). [2, 3]. Children are considered to be most vulnerable part of the world's population and are particularly considered to be at greater risk of lead poisoning than adults firstly, because they are highly expected to ingest lead as they can absorb a greater percentage of ingested lead per unit of a body's weight. Secondly, rapidly growing bodies and minds of children are more prone for to get affected by harmful impacts of lead [4].Health effects caused by lead poisoning vary with the intensity of lead in the environment, with exposure length of the lead and also with the developmental stages of the child. Sometimes accumulated lead within bones is released into the blood during pregnancy and can be as a source of exposure for the developing fetus [5]. This review aims to highlight the sources, possible health impacts, diagnosis, prevention and treatment associated with lead poisoning in childhood.

1.1 Sources of lead exposure

Children are more prone for the potential adverse impacts of lead poisoning because the intake of lead per unit of body is greater in young children than in adults as well the body systems of young children are undergoing rapid development hence their systems are not fully developed so they have increased chances for the uptake of lead .Young children are mostly involved in hand to mouth activity as they often place small objects in their mouths which results in possibility of intake of lead with dust and soil and also the route to exposure is increased in pica behavior which is the form of extreme hand to mouth activity[6]. Lead dust from lead based paints is another source of exposure for children as they are more prone to get affected by lead based paints in the older homes than by any other source. Most children plays outside their homes and ingest it directly through the exhausts of car or through open burning of waste in which lead is present or 
sometimes track its particles into their homes on the bottom of their shoes [7].

\subsubsection{Prenatal exposure to lead and exposure to lead in human milk}

If Lead is stored in the skeleton of mother in the past years, it may release into the circulation, of the metabolic stress of pregnancy. Lead may passes from the nurturing stage to the infant stage and the blood lead level of the infant may become similar to that of the mother lead level. Lead can also penetrate the infant's immature blood and enter the brain where it impairs the brain development. The human brain which is in a developing stage is more vulnerable to lead, even at a very low exposure concentrations [8]. The lead source in the blood of infant is a mixture of dietary and skeletal lead which is also shown by various studies which exhibited the variance in lead isotopes that are deposited and accumulated in the bones of women. Though lead may be present in human milk, the level is much closer to that of the plasma lead and very much lower than that which is found in the total blood which means that very little amount may get into the infants blood. Food and other things which are taken in by the infants may contain lead levels. Breastfeeding women with relative lead levels may cause less lead exposure to the infants than the women who don not breastfeed and rely upon other infant foods. In Mexico, women who take calcium supplements during the period of lactation may result in relatively small decrease in the mother's blood lead concentration, which is probably due to the decrease in the skeletal reabsorption [9].

\subsection{Health impacts caused by Lead Poisoning Children}

A wide range of toxicological disorders in children occurs due to the exposure of lead. Lead exposure leads to various kinds of diseases even at a very young age, it is associated to hearing loss, malfunctioning in vitamin D metabolism, stunted growth, adverse effects in kidneys, and decreased production of blood within the body. If the levels of lead, slightly increases in blood by $10 \mu \mathrm{g} / \mathrm{dL}$, it causes decrease in the intelligence level of the child[10]. These effects of lead poisoning outspread from symptomatic, clinically obvious and acute poisoning at the very high exposure levels to subclinical effects at lower levels but these low exposure levels are still very poisoning. Every organ of the child's body can highly affected by the lead poisoning. The main organs which are affected by the lead exposure are renal, gastrointestinal, cardiovascular, immune, endocrine, hematological, central and peripheral nervous systems [11].

\subsubsection{Acute clinical toxicity}

Symptomatic lead poisoning may occur in children due to the high dose of lead which results in acute clinical toxicity. The symptoms of lead poisoning in children are fatigue, constipation, anaemia, colic, and neurological structures that can differ in the exposure of different concentration levels. A fatal acute encephalopathy with ataxia, coma and convulsions may occur in the most severe cases. Sometimes, children who may survive with the acute lead poisoning may suffer from permanent shortfalls in their neurodevelopmental function. Obvious clinical symptoms and signs of lead poisoning are very common now days in low incomes countries and it's children population who are living near or around the sites which are highly polluted with lead levels. In comparison to this, these symptoms and signs are less common in the sites and countries where lead screening and monitoring of environment is performed on regular basis [12].

\subsubsection{Subclinical toxicity}

The subclinical effects of lead are not clinically very obvious but can have very much detrimental health impacts. The principle evidence of subclinical toxicity is mostly dependent on the concentration of dose which can have clinical effects, within childhood[8].

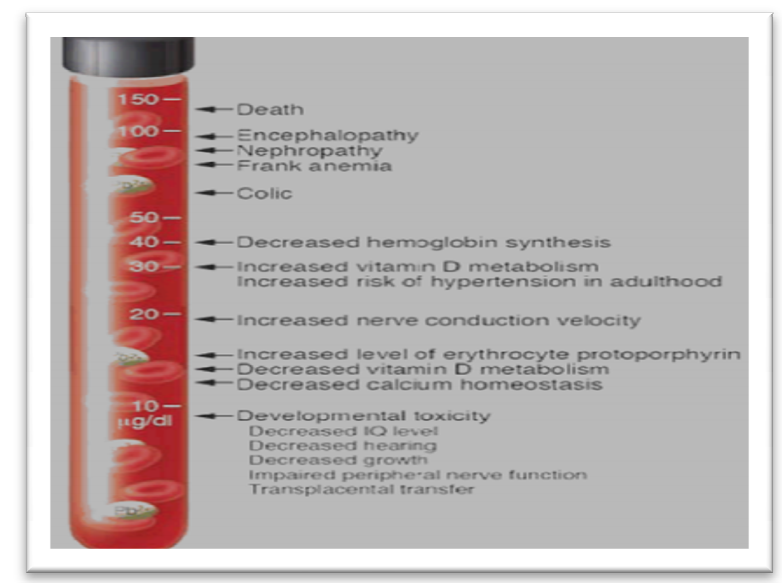

Fig.1: Pediatric effects of lead at various blood lead levels [8].

\subsubsection{Haematological toxicity}

Haematological toxicity is regarded as a clinical manifestation of lead poisoning in red blood cells which is basically involved in causing anemia. The occurrence and severity of lead induced anemia is associated directly with the blood lead levels of the children. Different studies show that, Iron deficient younger children are at a greater threat of lead induced clinical anemia[13].

\subsubsection{Neurological toxicity}

Lead poisoning may target the motor axons which are present in the peripheral nervous system. The irrational and neurotic changes in these fibers may involve the axonal degeneration and segmental demyelination. Since the time of Hippocrates, the wrist and ankle drop with the 
extensor muscle palsy which has been documented as the neurological and peripheral lead toxicity. Lead causes asymptomatic damage of neuro and behavioral functioning in the central nervous system of children. Previous studies have been conducted in 1970s which have shown link between intelligence quotient (IQ) and lead. Same results also have been shown in the previous studies[14] . On the basis of numerous studies in various countries it is projected that in the children of preschool years, almost about a quarter to a half of an IQ point is vanished for every increase of $1 \mu \mathrm{g} / \mathrm{dl}$ in the blood lead level. Whole blood levels is as low as 1-3 $\mu \mathrm{g} / \mathrm{dl}$ in the young children due to the toxicity of subclinical neurobehavioral[15].A study showed that data collected from 4800 children with age between 6-16 years. These children took part in the Third National Health and Nutrition Examination Survey in the United States, findings showed that there was an inverse relation between the math and reading scores and the blood lead level in the children who have lead level more than 5 $\mu \mathrm{g} / \mathrm{dl}$. Hence, the relationship between the lead levels and IQ loss is very much significant. Increase in the lead levels from less than $1 \mu \mathrm{g} / \mathrm{dl}$ to $0 \mu \mathrm{g} / \mathrm{dl}$ is linked with a decrease in 6 point of IQ which is noticeably much greater than the decrement linked with an increase in blood level from $10 \mu \mathrm{g} / \mathrm{dl}$ to $20 \mu \mathrm{g} / \mathrm{dl}$.

Relationship of Concurrent Blood Lead Concentration with Children's Intellectual Function

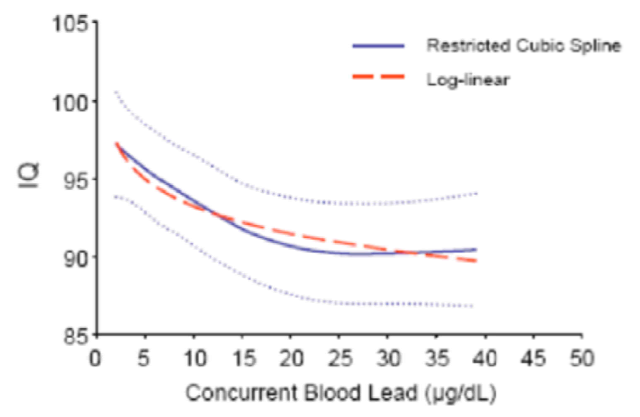

Fig.2: Relationship between concurrent blood lead level and children's IQ [15]

As the exposure of lead increases it results in the decreased mean IQ in children's population, this further results into a considerably increased number of children with lessened intelligence and mental impedance. The consequences are:

- A noticeably increase in the number of children who are weak in the studies and require speacial kind of education and other remedial programs.

- A decrease in country's leadership.

- A flapped gap in socioeconomic accomplishment between the countries with low and high levels of population that are exposed to lead [16].

\subsubsection{Other Health Impacts}

Children with lead level $70 \mu \mathrm{g} / \mathrm{dL}$ to $80 \mu \mathrm{g} / \mathrm{dL}$ may show very serious symptoms of encephalopathy. Encephalopathy is a disease that changes the structure and function of brain.[17] In the risky cases, it results in fits, coma or even death. In the early stages of this disease, the high levels of lead exposure in children causes stomach cramps and irritation but may turn into more severe symptoms such as clumsiness and vomiting. It is more dangerous than the extreme cases of the low lead poisoning levels in children which may cause little to no physical hazard but are still linked with the behavioral and neurological effects. Low lead exposures may cause neurodevelopmental problems, making scientist conclude that no level of lead exposure is good for the children[16]. Different researches show destructive effects of lead exposure in the children, damage in the functioning of brain, academic performance, motor skills, memory, and other problem solving skills. Additionally, the likelihood of ADHD, problems in brain functioning in children and also decrease in the volume of brain in the adulthood is reported. Lead exposure has been associated with the functions and impulse control, researchers have explored links in between blood lead concentrations and the behaviors which involve use of substance, criminal activity and other infections that are sexually transmitted [17].

In the year 2012, about 535,000 of U.S children between the age of 1 and 5 were found with high blood lead concentration. This amount may show a noticeable decrease as compared to the population in past few years [18] .Cultural and socioeconomic differences may still continue with the children in minority and families with low income may suffer from higher levels of blood lead. This is due to the disparities in the housing, living conditions and nutrition. Because the calcium reduces the amount of lead absorption within the body, this disease is greatly faced by the malnourished children [19].

\subsection{Diagnosis of lead poisoning}

Lead concentration in blood can be diagnosed through blood tests. Permissible range for lead level in blood, must be lesser than $10 \mathrm{mcg} / \mathrm{dL}$. For children, the level greater than $45 \mathrm{mcg} / \mathrm{dL}$ should always be treated [20].

\subsection{Treatment}

The treatment method used depends upon the concentration level of lead in blood. The source is removed in case of mild lead poisoning but in case of severe lead poisoning the lead can be extracted with the help of chelation therapy. Activated charcoal method can also be used as a treatment method as it binds lead with gastrointestinal tract and encourages lead removal through defecation [20].

\subsection{Implications for Lead Poisoning Prevention}


Prevention, Control and Eradication in the level of lead exposure from the environment is necessary, so that lead exposure to children can be reduced. It is important to reduce or eliminate the blood lead level as much as possible and This elimination will require collaboration and participation of governments at all levels. Because this can never be accomplished without applying all the prevailing standards which ensure that lead levels are in a continuity of declination [21].

\section{ACKNOWLEDGEMENTS}

Authors would like to thanks Environmental Science Department, Kinnaird College for Women, Lahore.

\section{REFERENCES}

[1] Mary Jean Brown, Michael E. Kashtock, David E. Jacobs, Elizabeth Whelan, Joanne Rodman, Michael R. Schock, Alma Padilla and Thomas Sinks, Lead Exposures in U.S. Children, 2008: Implications for Prevention. Environmental Health Perspectives .2008; 16: 220-228.

[2] Gould E. Childhood lead poisoning: conservative estimates of the social and economic benefits of lead hazard control. Environ. Health Perspect. 2009; 117(7):1162-1167.

[3] Trasande L and Liu Y. Reducing the staggering costs of environmental disease in children, estimated at \$76.6 billion in 2008. Health Affairs. 2011;30(5):863-869.

[4] Chandramouli K, Steer CD, Ellis M, Emond AM. Effects of early childhood lead exposure on academic performance and behavior of school age children. Arch. Dis. Child. 2009;94 (11):844-848.

[5] Jeanne Brooks,Gunn Greg J. Duncan .The Effects of Poverty on Children . the Future of children and poverty. 2007;7(2)

[6] Mushak P. Defining lead as the premier environmental health issue for children in America: criteria and their quantitative application. Environmental Research, 2012, 59: 281-309. 25.

[7] Tong S, McMichael AJ. The magnitude, persistence and public health significance of cognitive effects of environmental lead exposure in childhood. Journal of Environmental Medicine, 2013, 1: 103-110.

[8] Healthy People 2020 Objective Topic Areas. U.S. Department of Health and Human Services. 2010:1335.

[9] DDH. State Health Department Announces Preliminary Findings in Blood Lead Level Study. November 5, 2008. North Dakota Department of Health, Bismarck, North Dakota, USA.
[10] Centers for Disease Control. Blood Lead Levels in Children Aged 1-5 Years-United States, 19992010. MMWR 2013;6;245-248

[11]Dietrich, k. N., m. D. Ris, p. A. Succop, o. G. Berger, and r. L. Bornschein. Early exposure to lead and juvenile delinquency. Neurotoxicology and Teratology. . 2001; 23:511-518

[12] Chandramouli K, Steer CD, Ellis M, Emond AM. Effects of early childhood lead exposure on academic performance and behaviour of school age children. Arch. Dis. Child. 2009;94(11):844-848.

[13] Tong S, Baghurst P, McMichael A, Sawyer M, Mudge J. Lifetime exposure to environmental lead and children's intelligence at 11-13 years: the Port Pirie cohort study. BMJ ;2006; 312: 1569-75.

[14] Canfield RL, Henderson CRJ, Cory-Slechta DA, Cox C, Jusko TA, Lanphear BP. Intellectual impairment in children with blood lead concentrations below 10 microg per deciliter. $N$. Engl. J. Med. 2003;348(16):1517-1526.16

[15] Ahamed M, Verma S, Kumar A, Siddiqui MK. Environmental exposure to lead and its correlation with biochemical indices in children. Sci Total Environ. 2005;346:48-55.

[16] Gatsonis, C. A.. \& Needleman, H. L. Recent epidemological studies of low-level lead exposure and the IQ of children: a meta-analytic review In Human Lead Exposure, ed H. L. Needleman, CRC Press, 2012

[17] Goodlad, J.K.; Marcus, D.K.; Fulton,. Lead and Attention-Defecit/Hyperactivity Disorders(ADHD) Symptoms:A Meta-Analysis Clinical Psychology Review,April 2013,33(3).

[18]Hu, H.; Scheidell, J.; Xu, X.; Coatsworth, A.M.; Khan, M.R. Associations Between Blood Lead Level and Substance Use and Sexually Transmitted Infection Risk Among Adults in the United States.Environmental Research, November 2014, Vol. 135.

[19] Fewtrell LJ, Pruss-Ustun A, Landrigan P, AyusoMateos JL. Estimating the global burden of disease of mild mental retardation and cardiovascular diseases from environmental lead exposure. Environ. Res. 2004;94(2):120-133.

[20]Gould ,Childhood Lead Poisoning: Conservative Estimates of the Social and Economic Benefits of Lead Hazard Control, E. Environmental Health Perspectives, July 2009, Vol. 117(7).

[21] Needleman, H. L., Schell, A., Bellinger, D., Leviton, A., and Allred, E. N. Long term effects of childhood exposure to lead at low dose: an eleven year followup report. N. Engl. J. Med. 322: 82-88. 